\title{
Adaptive versus Proactive Behavior in Service Recovery: The Role of Self-Managing Teams
}

\author{
Ad de Jong $^{\dagger}$ and Ko de Ruyter \\ Department of Marketing, Faculty of Economics and Business Administration, \\ Maastricht University, P.O. Box 616, NL-6200 MD Maastricht, The Netherlands, \\ e-mail:a.dejong@mw.unimaas.nl,k.deruyter@mw.unimaas.nl
}

\begin{abstract}
In this article, we develop a conceptual model of adaptive versus proactive recovery behavior by self-managing teams (SMTs) in service recovery operations. To empirically test the conceptual model a combination of bank employee, customer, and archival data is collected. The results demonstrate support for independent group-level effects of intrateam support on adaptive and proactive recovery behavior, indicating that perceptual consensus within service teams has incremental value in explaining service recovery performance. In addition, we provide evidence that adaptive and proactive recovery behavior have differential effects on external performance measures. More specifically, higher levels of adaptive performance positively influence customer-based parameters (i.e., service recovery satisfaction and loyalty intentions), while employee proactive recovery behavior contributes to higher share of customer rates.
\end{abstract}

Subject Areas: Hierarchical Linear Modeling, Organizational Behavior, Self-Managing Teams, Service Management, and Service Recovery Performance.

\section{INTRODUCTION}

It has been argued that service recovery is a crucial element of any service management strategy (Bell \& Zemke, 1987; Boshoff, 1999; Bowen \& Johnston, 1999; Smith \& Bolton, 1998). As customer reactions to service failures frequently involve personal, ill-defined, or complex problems, many theorists recognize that the best way to recover service failures is to empower front-line service workers to identify and solve them (Bitner, Booms, \& Tetreault, 1990; Hart, Heskett, \& Sasser, 1990; Hocutt \& Stone, 1998). In order to adequately respond to this managerial practice a growing number of companies are restructuring their front-line service operations around self-managing teams (SMTs) (Batt, 1999; Wageman, 1997). SMTs are based on the notion that employees share the collective responsibility for their work, for monitoring their own performance, and adapting work routines in response to a variety of circumstances.

\footnotetext{
${ }^{\dagger}$ Corresponding author.
} 
In service recovery, the employees' ability to adapt to the specific problem situation is particularly important (Boshoff \& Leong, 1998; Hartline \& Ferrell, 1996). In addition to adaptive behavior, it has also been argued that front-line service workers need to be proactive by, for instance, soliciting suggestions from customers, detecting and correcting causes of service problems and challenging existing routines (e.g., Iacobucci, 1998; Van Looy, Desmet, Krols, \& Van Dierdonck, 1998). It has been found that "unprompted and unsolicited employee actions" caused 55\% of all reported highly positive customer experiences with the service delivery in general (Wels-Lips, Van der Ven, \& Pieters, 1998). While positive effects of adaptive and proactive behavior have been documented recently in relation to sales force performance (Pitt, Ewing, \& Berthon, 2002; Spiro \& Weitz, 1990) and service delivery in general (Wels-Lips et al., 1998), little is known about adaptive and proactive employee behavior with regard to service recovery. Given the fact that many firms are still experimenting with how to utilize forms of self-management for front-line service functions and empirical results are often anecdotal and sometimes contradictory (Wageman, 1997), there is a need for a more in-depth understanding of adaptive and proactive behavior by members of SMTs in the context of service recovery. By addressing this need, our study aims to contribute to service management theory and practice. We seek to advance the knowledge on the role of SMTs in service recovery operations in several ways.

First, we develop a conceptual framework that distinguishes between adaptive and proactive behavior and identifies a number of antecedents of both types of behaviors in the context of service recovery. Specifically, we examine how characteristics of the SMT, as well as the organizational context in which the SMT operates influence SMT member adaptive and proactive recovery behavior.

Second, as service recovery effort represents a collective responsibility of SMTs, adaptive and proactive recovery behavior may not only differ between individual team members, but also between teams. In other words, what drives behavior in one group may differ from what determines behavior in another. Each group may develop a unique set of standards of desirable adaptive and proactive behavior, leading to differences between groups (Mathieu \& Kohler, 1990). Hence, the effect of behavioral predictors may not only vary at the level of the individual team member, but also at the group level (Neuman \& Wright, 1999; Ostroff, 1993). Given the fact that the service recovery effort is the collective responsibility of SMTs, we propose to examine whether behavior-shaping factors have an impact at the group level of analysis (Kidwell \& Mossholder, 1997; Van Yperen \& Snijders, 2000). Such an approach has been left virtually unexplored in the service recovery literature so far.

Third, little is known about the impact of adaptive and proactive employee behavior in SMTs on service recovery performance measures. Since service recovery behavior involves interactions with customers, it seems necessary to take customer-based parameters (e.g., service recovery satisfaction and return intentions) into account as measures of service recovery effectiveness. Frequently, these do not correlate with quantifiable, behavioral-based productivity measures (e.g., revenues and sales) that are often used in team performance assessments, resulting in the so-called performance paradox of team performance (Spreitzer, Cohen, 
\& Ledford, 1999). We extend previous team performance research by examining the impact of adaptive and proactive service recovery behavior on both types of performance parameters.

Our article is structured as follows. We develop a conceptual framework by discussing adaptive and proactive behaviors in the context of service recovery and by identifying their antecedents as well as consequences. Subsequently, we present the results of an empirical study about the service recovery practices of the members of 61 SMTs in a large bank and their customers. We conclude the article by discussing our findings, as well as the theoretical and managerial implications that follow from our study.

\section{CONCEPTUAL FRAMEWORK}

\section{Adaptive and Proactive Recovery Behavior}

Problems that occur during service delivery are often complicated, ill-defined, and idiosyncratic in nature and lie beyond standard service delivery procedures (Hart et al., 1990). As a result, effective service recovery performance typically requires extra-role behaviors that include adaptive and proactive components (Hartline \& Ferrell, 1996; Morrison \& Phelps, 1999). These behavioral components may be closely related, but are distinctive in nature, as Pulakos, Arad, Donovan, and Plamondon (2000) demonstrate. In this article, we differentiate between adaptive and proactive behavior as distinct components that are complementary to the establishment of an effective service recovery strategy.

Numerous authors have discussed adaptive performance in a multitude of areas, such as selling (Spiro \& Weitz, 1990), learning (London \& Mone, 1999), training (Pulakos et al., 2000), and servicing (Hartline \& Ferrell, 1996). Adaptive performance typically involves a multiplicity of behaviors related to different work environments. Examples of adaptive performance are creative problem solving, coping with complex and unpredictable work situations, adjustment to technological innovations, and interpersonal adaptability. In service recovery, the interpersonal interaction between service providers and customers is a hallmark feature (Bitner, 1990) and it is argued that the service employee's interpersonal adaptability is of major relevance. Empirical findings consistently suggest that front-line employees need to adjust their behavior to properly manage and alleviate customer complaints (Halstead, Droge, \& Cooper, 1993; Spreng, Harrell, \& Mackoy, 1995). Hartline and Ferrell (1996) define adaptability in a service context as "the ability of contact employees to adjust their behavior to the interpersonal demands of the service encounter" (p. 55). Due to the atypical, complex, and disturbing nature of service recovery problems, employees need to show flexibility in their contact with customers (e.g., Hatano \& Inagaki, 1986; Holyoak, 1991). In the context of SMTs, this aspect of performance requires the employees to bring complex matters or situations collectively to their desired end or to jointly develop creative solutions in response to novel difficult problems indicated by customers. Accordingly, adaptive service recovery involves adjusting behavior to optimally respond to customers' complaints (e.g., Solomon, Surprenant, Czepiel, \& Gutman, 1985). 
In addition to adaptability, the organizational behavior and team literature have investigated "proactive personality and behaviors" as another job performance success factor (e.g., Aspinwall \& Taylor, 1997; Bateman \& Crant, 1993, 1999; Crant, 1995, 2000; Hyatt \& Ruddy, 1997; Kirkman \& Rosen, 1999; Pitt et al., 2002; Seibert, Crant, \& Kraimer, 1999). Furthermore, Kirkman and Rosen (1999) demonstrate that "proactivity" is an indicator of SMT effectiveness. In recent service marketing research too, there has been growing interest in proactive service approaches by employees (e.g., Peccei \& Rosenthal, 1997, 2001). Proactive behavior concerns other actions than adaptive behavior, or as Bateman and Crant (1999, p. 63) state: "proaction involves creating change, not merely anticipating it." While adaptive skills include listening to and considering customers' viewpoints and opinions in order to appropriately adjust their service approach, proactive behavior involves behavioral initiative aimed at improving the current work circumstances in general or creating new ones. It involves challenging the status quo of the operational aspects of the service delivery process rather than passively adapting to the present service conditions (e.g., Iacobucci, 1998; Morrison \& Phelps, 1999). Particularly in the case of reoccurring service failures, which are caused by inadequacies of the current service delivery system, it is of importance for employees to take behavioral initiative to change existing workplace practice in order to prevent customer complaints in future (Hart et al., 1990). Moreover, spontaneous employee initiatives have been shown to be successful predictors of high levels of satisfaction and customer delight (Wels-Lips et al., 1998).

\section{Antecedents of Adaptive and Proactive Recovery Behavior}

We discern three types of antecedents that may influence service recovery performance of SMTs (e.g., Emery \& Fredenhall, 2002; Helfert \& Vith, 1999; Spreitzer et al., 1999). Three determinants seem of particular interest: (1) higher levels of empowerment (Bowen \& Lawler, 1992, 1995a, 1995b; Hart et al., 1990), (2) facilitative organizational conditions with regard to customer complaint management (e.g., Bowen \& Johnston, 1999), and (3) interteam and intrateam support in the service recovery effort (e.g., Sergeant \& Frenkel, 2000). Since the focus in the aforementioned studies has been on the individual employee, we propose predictor-criterion relationships at the individual level in this paragraph.

It has been argued that empowerment is a requirement for a flexible work approach and behavioral initiatives to make on-the-spot decisions to optimally satisfy customers (Hartline \& Ferrell, 1996; Iacobucci, 1998; Spreitzer, 1995; Van Looy et al., 1998). Recent research has empirically confirmed the positive influence of empowerment on employees' adaptability toward service customer requests (Chebat \& Kollias, 2000). In addition, Spreitzer (1995) states that empowerment also leads to a proactive orientation toward jobs, management, and organizations, resulting in innovative behavior. Furthermore, Van Looy et al. (1998) demonstrate that empowerment of service employees is positively related to various innovative behaviors, including problem recognition, idea generation, getting support for new ideas and commitment to innovations. Kirkman and Rosen (1999) show that team empowerment positively affects team proactivity. Similarly, Wellins, Byham, and 
Wilson (1991) provide evidence that empowered teams are more likely to engage in initial behaviors to solve existing work problems. Hence, we state that:

H1: There will be a positive effect of empowerment on (H1a) adaptive recovery behavior and $(\mathrm{H} 1 \mathrm{~b})$ proactive recovery behavior.

Numerous studies have emphasized the importance of facilitative organizational arrangements, such as organizational procedures and policies to support service recovery work (e.g., Armistead \& Clark, 1994; Bell \& Zemke, 1987; Bitner et al., 1990; Bowen \& Johnston, 1999; Hart et al., 1990; Johnston, 1995). One major organizational aspect in relation to service recovery concerns customer complaint management, which involves managing the provision of information and feedback about customer complaints and evaluations to front-line employees (Lawler, 1986; Ledford, 1993; Schneider, White, \& Paul, 1998). Hartline and Ferrell (1996) demonstrate that a managerial focus on behavioral-based employee performance aspects, such as efforts to increase the flexibility of existing service procedures and the allocation of resources to improve service delivery efforts, eventually have a positive impact on employees' adaptability to meet customer requests. Customer complaint management also stimulates service improvement employee initiatives and efforts on behalf of the customers (Peccei \& Rosenthal, 2001). Bansal, Mendelson, and Sharma (2001) argue that information sharing within the organization usually includes suggestions to change existing procedures and might encourage front-line employees to take reasonable action and to exert change efforts. Hence, we hypothesize that:

$\mathrm{H} 2$ : There will be a positive effect of customer complaint management on $(\mathrm{H} 2 \mathrm{a})$ adaptive recovery behavior and $(\mathrm{H} 2 \mathrm{~b})$ proactive recovery behavior.

It has been recently argued that teamwork or an internal service orientation among employees supporting each other concerns another crucial determinant of service recovery performance (Boshoff \& Allen, 2000). Interteam support refers to the internal service and communication between teams and other units within the organization, while intrateam support concerns the mutual willingness of team members to help and to deliver service to each other to reach common group goals (Campion, Medsker, \& Higgs, 1993). It has been argued that well-functioning interpersonal processes among employees stimulate an atmosphere of idea generation and creativity (Andrews, 1995), which is especially relevant in service recovery. Cooperative support within and between teams is crucial to adaptive behavior. When service employees experience interpersonal adaptability from their colleagues, they will be motivated to carry over this adaptive approach in their encounters with customers. In addition to increased levels of adaptability, interteam and intrateam support are also influential in relation to proactive behaviors. Scott and Bruce (1994) have stated that high frequencies of team member exchanges accumulate the availability of additional resources such as idea sharing and feedback available to employees. This peer-based learning strengthens employees' intention to engage in innovative behavior. Furthermore, Sergeant and Frenkel (2000) demonstrate that cooperative interaction and information sharing within teams and with other teams in organizations makes employees more confident about their own 
abilities to satisfy customers. Finally, Morrison and Phelps (1999) have argued that work group norms that support and encourage change motivate employees to take charge, because they perceive doing so as a way to get approval from fellow team members. We hypothesize:

H3: There will be a positive individual-level effect of interteam support on $(\mathrm{H} 3 \mathrm{a})$ adaptive recovery behavior and $(\mathrm{H} 3 \mathrm{~b})$ proactive recovery behavior.

H4: There will be a positive individual-level effect of intrateam support on $(\mathrm{H} 4 \mathrm{a})$ adaptive recovery behavior and $(\mathrm{H} 4 \mathrm{~b})$ proactive recovery behavior.

Because service recovery in SMTs is essentially a collective responsibility, we discuss whether there is incremental value in positioning aforementioned predicator-criterion relationships at the group level of analysis in the next paragraph.

\section{Assessment of Predictor-Criterion Relationships Across Levels of Analysis}

Group-level assessments of the antecedents represent shared team member perceptions of the organizational environment (e.g., empowerment) and work group practice (i.e., intrateam support). It has been argued that interpersonal processes within groups influence group performance. Each team may develop its own norms and standards regarding appropriate behavior (e.g., the level of support to colleagues), which is reflected by between-groups differences (Mathieu \& Kohler, 1990). These compositional group-level effects stem from explicit and implicit social processes within the team. First, social presentation and cognitive consistency needs (Festinger, 1954) drive individual employees to purposely use cognitive and affective strategies to influence the perceptions of other team members (e.g., by exhibiting enthusiasm at helping colleagues) as a way to attain socially appropriate results. Second, group processes also operate in an implicit manner. Previous research has provided evidence that members in groups without conscious awareness imitate other members through vicarious learning, groupthink, etc. (e.g., Bandura, 1986; Bartel \& Saavedra, 2000). Third, in-group and out-group dynamics form a crucial cause of differentiated shared beliefs across teams. Social identity theory (Tajfel $\&$ Turner, 1985) suggests that individuals use identification with social groups to define their self-concepts. In order to acquire positively defined self-concepts, individuals are more inclined to identify with clearly delineated and high-status groups that are surrounded by comparable rival out-groups (Ashforth \& Mael, 1989; Houston, Walker, Hutt, \& Reingen, 2001). Fourth, group-level effects may also stem from information sharing within teams, which diverges across groups, and from differences in shared experiences between groups (cf. Van Yperen \& Snijders, 2000). Therefore, aggregation of individual-level perceptual measures seems necessary to properly consider these group-level phenomena and examine additional cross-level relationships between group-level predictors and individual-level behaviors. Previous empirical research on withdrawal behavior in service operations (Blau, 1995; Mathieu \& Kohler, 1990) has revealed that group-level specifications 
of variables explain a significant amount of extra variance in individual employee outcomes beyond individual-level assessments. These findings confirm the idea that group-level aggregations of contextual properties contain an additional compositional effect, which is not considered by individual-level assessments (Bliese, 2000; Ostroff, 1993). Hence, we posit that:

H5: At the group level of analysis there will be positive effects of (H5a) empowerment, (H5b) customer complaint management, (H5c) interteam support, and (H5d) intrateam support that account for a significant amount of additional variance in individual employee perceptions of adaptive recovery behavior.

H6: At the group level of analysis there will be positive effects of (H6a) empowerment, (H6b) customer complaint management, (H6c) interteam support, and (H6d) intrateam support that account for a significant amount of additional variance in individual employee perceptions of proactive recovery behavior.

\section{Consequences of Adaptive and Proactive Recovery Behavior}

In addition to predictors of service adaptive and proactive recovery behavior by SMTs, it is of interest to examine their consequences. In the evaluation of service firm effectiveness, the distinction between customer-based criteria (e.g., customer satisfaction and customer loyalty) and quantifiable behavioral-based productivity measures (e.g., revenues, sales; e.g., Anderson, Fornell, \& Rust, 1997; Heskett, Sasser, \& Schlesinger, 1997) is often made. Previous research has related adaptability to various performance measures. Spiro and Weitz (1990) have argued that adaptive selling practice is likely to result in better sales performances, as sales employees have the capability to adapt to differential service situations. Employee adaptability also has been linked to customers' perceptions of the service encounter. Humphrey and Ashforth (1994) have demonstrated that front-line employees are less able to appropriately meet the considerably varying customer requests when they merely carry out scripted rules. Bitner et al. (1990) and Bitner, Booms, and Mohr (1994) show that employees who adapt their approach to meet special customer demands and concerns receive more positive customer evaluations. Alternatively, Kirkman and Rosen (1999) provide empirical evidence that team proactivity is positively related to a number of crucial effectiveness criteria, including organizational commitment, job satisfaction, customer service, and productivity. Finally, at the firm level, Rust, Danaher, and Varki (2000) have reported that proactive changes in service quality and price strategies lead to improvements in market share. In sum, these studies together suggest that adaptive and proactive behaviors are important elements of service company performance.

Previous research has demonstrated that adaptive as well as proactive behaviors are positively related to customer evaluations of the service encounter (Bitner et al., 1990, 1994; Kirkman \& Rosen, 1999). Besides these psychological outcomes, it has been contended that the behavioral parameter "share of customer," or the number of services purchased from a specific front-line employee, forms another criterion of marketing performance (Babin \& Attaway, 2000). The 
underlying rationale is that the effect of customer service policies and practices should also become visible in customer behavior, because customer quality evaluations and purchase behavior are significantly related. Therefore, these parameters need to be simultaneously investigated when striving for higher profitability rates (Soteriou \& Zenios, 1999). Frequently, service firms also use traditional productivity measures to gauge the performance of service employees, such as volume of services sold (Singh, 2000). It has been argued that, particularly in highly customized services, an underlying tension exists between customer demands (demanding excellent service recovery quality) and productivity goals. Frequently, it takes service providers a relatively large amount of time to solve service problems adequately in the eyes of the customer. Alternatively, the amount of time reserved to deal with service recovery issues should be restricted in order to have enough time left to sell financial service products (Batt, 1999). Therefore, trade-offs are required between employing customer-based versus productivity-oriented performance parameters (Anderson et al., 1997; Singh, 2000). Hence, we expect that a strong focus on adaptive and proactive recovery behavior in SMTs as a strategy to solve service failures may result in lower productivity rates. Therefore, we posit that:

H7: There will be positive effects of (H7a) adaptive recovery behavior and $(\mathrm{H} 7 \mathrm{~b})$ proactive recovery behavior on service recovery satisfaction.

H8: There will be positive effects of (H8a) adaptive recovery behavior and $(\mathrm{H} 8 \mathrm{~b})$ proactive recovery behavior on loyalty intentions.

H9: There will be positive effects of (H9a) adaptive recovery behavior and (H9b) proactive recovery behavior on share of customer.

H10: There will be negative effects of (H10a) adaptive recovery behavior and (H10b) proactive recovery behavior on service revenues.

Aforementioned hypotheses are summarized in the following conceptual model (Figure 1).

\section{EMPIRICAL STUDY}

\section{Research Setting}

Employees from SMTs of a large Dutch bank, as well as their customers, were surveyed. The bank is a cooperative organization comprising members, not shareholders, and having a decentralized structure that consists of local branch offices with a local stronghold. Local subsidiaries have a relatively high level of autonomy in service recovery decision making. The bank employs approximately 48,000 people and has 424 branch offices all over the country in order to keep a high local presence. It operates both in business and in consumer markets and strives for service excellence as a critical strategy to marketing success. Within each branch separate SMTs are responsible for solving service problems in different segments. 
Figure 1: Relationships in the conceptual framework.

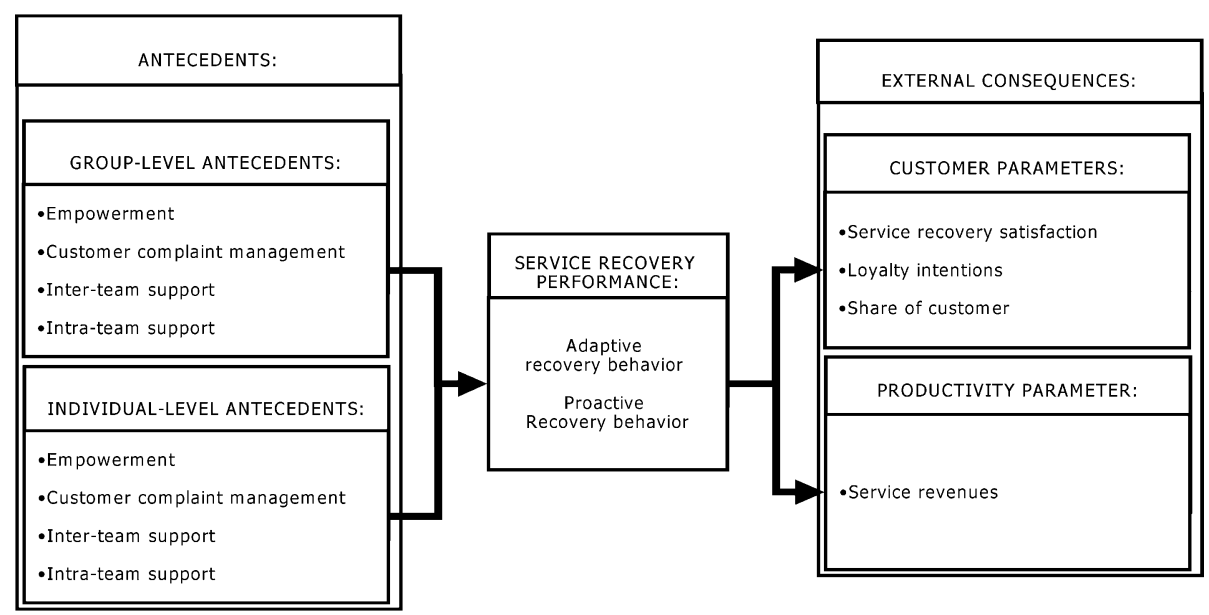

Table 1: Examples of adaptive and proactive recovery behavior as specified by bank.

Adaptive Recovery Behavior

- Quickly providing alternatives for compensating customers when the bank charges too much for changing currency.

- Being flexible in modifying routines after customers experience problems with particular service issues.

- Carefully listening to and taking into account the customer perspective concerning misleading information about the opening times.

- Apologizing for slow and unavailable service.

- Taking appropriate action when the ATM has defect; quickly providing creative solutions to customers.

Proactive Recovery Behavior

- Anticipating customer problems related to online banking systems by opening a customer complaint phone number.

- Taking preventive action as a team by organizing group meetings in order to learn how to deal with the weaknesses of new online-based service delivery routines.

- Organizing brainstorm sessions on customer service routines with other teams.

- Implementing spreadsheet-based analyses and generating new innovative ideas to address structural service problems.

- Actively scanning/monitoring the need for change and innovation.

A distinction is made between nonroutine or knowledge-intensive services, such as investment counseling, trust services, business consulting, and estate planning, and routine services or transaction-intensive services, such as checking and savings accounts, currency exchange, and credit application accounts. In Table 1 we present a number of examples of adaptive and proactive recovery behavior that are listed in the bank's service training manuals. 


\section{Sampling and Surveying}

Data were collected via self-report questionnaires from individual employees organized in SMTs and from their customers. Mail questionnaires were sent to employees as well as customers of 61 SMTs. For the employee survey, all members of the SMT were invited to participate. In total, 939 questionnaires were returned (76.4\%). For the customer survey, a random sample of 150 customers per SMT was drawn. In total, 1,884 questionnaires were returned to the researchers by mail (20.6\%). For the employee survey, 809 questionnaires from 61 teams were used for further analysis. Regarding the customer survey, 1,724 questionnaires of customers of the 61 service teams were employed for the analysis. For the employee survey, the following sample profile emerges: Fifty-four percent of the employees are younger than 31 years. Furthermore, a large part of respondents are high school graduates $(45.5 \%)$ and/or have completed tertiary education $(30.8 \%)$. Besides this, most respondents have been with the institution for a relatively longer period $(55.9 \%>4$ years). For the customer survey, the following sample profile was acquired: Most respondents were male (63.8\%) and older than 44 years (59.2\%). The great majority of the respondents had a long-lasting relationship with the bank $(93.5 \%>5$ years) and about half of them visited the bank at least once a month $(46.5 \%)$.

To obtain more insight into nonresponse bias those employees who did not participate in the mail survey were asked to answer an abbreviated telephone survey. In general, no significant differences between respondents and nonrespondents were found. A similar procedure was carried out in relation to the customer survey data. Again, we did not discover any significant differences between respondents and nonrespondents. Furthermore, since it has been posited that late respondents are more similar to nonrespondents, we also compared early respondents with late respondents (Armstrong \& Overton, 1977). Generally, the results revealed no significant differences between early and late respondents of both data sets, which implies that no serious response-related problems were encountered.

\section{Measurement Issues}

All scale items of the employee survey were measured with a seven-point scale, ranging from "strongly disagree" (1) to "strongly agree" (7) and were developed mainly on the basis of validated scales. The assessment of adaptive recovery behavior was based on a 16-item adaptive selling scale developed by Spiro and Weitz (1990). To measure adaptive recovery behavior, we modified this scale by dropping redundant items and rewording the remaining items to emphasize team and service recovery aspects. The final six-item scale assesses team members' ability to adapt to diverse service recovery situations by altering their approach toward customers. Proactive recovery behavior largely consisted of items from an instrument developed by Hyatt and Ruddy (1997). To determine the discriminant validity of adaptive and proactive recovery behavior, we tested a common-factor model and a two-factor model for the items of these constructs. All fit indices of the two-factor model $\left(\chi^{2}(\mathrm{df})=460.46(53), \mathrm{PNFI}=.78, \mathrm{GFI}=.94, \mathrm{AGFI}=.91, \mathrm{RMSEA}=.08\right.$, $\mathrm{NFI}=.97, \mathrm{CFI}=.98)$ provide a better fit than those of the common factor model $\left(\chi^{2}(\mathrm{df})=2,915.96(54), \mathrm{PNFI}=.72, \mathrm{GFI}=.71, \mathrm{AGFI}=.57, \mathrm{RMSEA}=.21\right.$, 
$\mathrm{NFI}=.89, \mathrm{CFI}=.89)$. Specifically, the two-factor model appears to have a significantly lower $\chi^{2}$-value than the common factor model $\left(\Delta \chi^{2}(1)=2,455.50\right.$; $p<.001)$, indicating that adaptive and proactive recovery behavior are distinctive constructs (cf. Mulaik et al., 1989).

The empowerment scale (seven items) was largely based upon the tolerance of freedom instrument of the LBDQ XII, which measured the amount of autonomy delegated to employees to self-manage their daily task responsibilities (Cook, Hepworth, Wall, \& Warr, 1981). The operationalization of customer complaint management was based on a scale developed by Schneider et al. (1998). More specifically, we reworded scale items to assess upper-level management's (1) solicitation and use of customer reactions regarding service quality and (2) the provision of customer complaint information to the service team. Interteam and intrateam support were measured using items adapted from scales developed by Campion et al. (1993).

We used two different techniques to examine the factor structure and item loadings. To begin with, we examined coefficient alphas, and the factor structure (through principal component analysis) for all the scale items simultaneously. A sixfactor structure was attained with items loading on the assumed dimensions. Next, we applied confirmatory factor analysis (CFA), employing LISREL (Jöreskog \& Sörbom, 1993) to determine the major measurement characteristics of the scales. The fit indices of the proposed factor model, construct reliabilities of the scales, and confirmatory factor loadings with $t$ values for each item are represented in Table 2 . The indices of the proposed factor model yielded a good fit (GFI $=.91$, AGFI $=$ .90$, RMSEA $=.047, \mathrm{NFI}=.91, \mathrm{CFI}=.94)$, revealing unidimensionality of the scales (Steenkamp \& Van Trijp, 1991). In addition, all measures have Cronbach's alphas of .71 or higher, indicating that the reliability of all constructs was acceptable (Nunnally \& Bernstein, 1994).

Next, we investigated the significance and magnitude of the item loadings to test within-method convergent validity. All items loaded significantly on their respective construct (minimum $t$ value $=13.50$ ) and had a standardized loading of at least .47. Furthermore, a procedure was followed to evaluate discriminant validity by testing whether pairs of constructs were correlated less than once. $\chi^{2}$ difference tests with $1 \mathrm{df}$ were used to test for unity between pairs of constructs. All tests were significant at the .05 significance level (cf. Anderson \& Gerbing, 1988).

Subsequently, the demographic variables education, organizational tenure, age, and the group design variables "team size," "percentage of front office activities" (i.e., direct customer contact responsibilities), nonroutine services served as control variables in testing the hypotheses. More specifically, nonroutine services involve a dummy that indicates the type of service setting in which the team operates (routine services vs. nonroutine services).

By means of a customer survey we assessed service recovery satisfaction, loyalty intentions, and share of customer. Service recovery satisfaction was assessed by a five-point single-item scale ranging from "strongly dissatisfied" (1) to "strongly satisfied" (5). In addition to this, we did include an extra answer category "not applicable" (6), to exclude those customers who did not have any recovery experiences from the analysis. We employed a single-item scale, as it has been argued that the use of multiple-item satisfaction scales may be disadvantageous to 
Table 2: Measures and validation.

\begin{tabular}{lc}
\hline & Factor \\
Measures & Loading $t$ Value \\
\hline
\end{tabular}

Employee Data

Fit Indices: $(\mathrm{GFI}=.91 ; \mathrm{AGFI}=.90 \mathrm{RMSEA}=.047 ; \mathrm{NFI}=.91 ; \mathrm{CFI}=.94)$

Empowerment $(n=6 ; \alpha=.89)$

1. In our team we are permitted to use our own judgment in $\quad .72$ solving problems.

2. In our team we are encouraged to take initiative. $\quad 65$

3. Our team is allowed a high degree of initiative.

4. In our team we are allowed complete freedom in our work. $\quad .85$

5. In our team we are allowed to do our work the way we think $\quad .75$ best.

6. As a team we are able to handle all tasks assigned to us.

Customer Complaint Management $(n=5 ; \alpha=.85)$

1. In our bank external customer complaints are used to evaluate the quality of the delivered services.

2. Our bank informs our team about customer evaluations of service recovery delivered by our team.

3. Our bank regularly asks our team to report possible customer complaints about the service delivered by our team.

4. Following customer reactions, our bank continuously adjusts the service delivery process.

5. Management of our bank seriously considers customer reactions.

Interteam Support ( $n=7 ; \alpha=.84)$ (one-reversed item)

1. Other teams act in a responsive manner when we forward customer complaints.

2. The knowledge of other teams assists us in serving customers.

3. The quality of service delivered by other teams to our team is good.

4. Because of insufficient feedback from other teams our service to customers is substandard. (reversed item)

5. Other teams provide good feedback on how to serve customers.

6. The cooperation between teams within the bank is good.

7. The employees of other teams are helpful in solving problems of customers.

Intrateam Support $(n=4 ; \alpha=.71)$

1. In our team we help each other in serving the customer.

2. The mutual support of team members is highly valued.

3. Each team member is personally responsible for the

4. In our team members need not formally be monitored with regard to the assistance of colleagues. 
Table 2: Measures and validation. (continued)

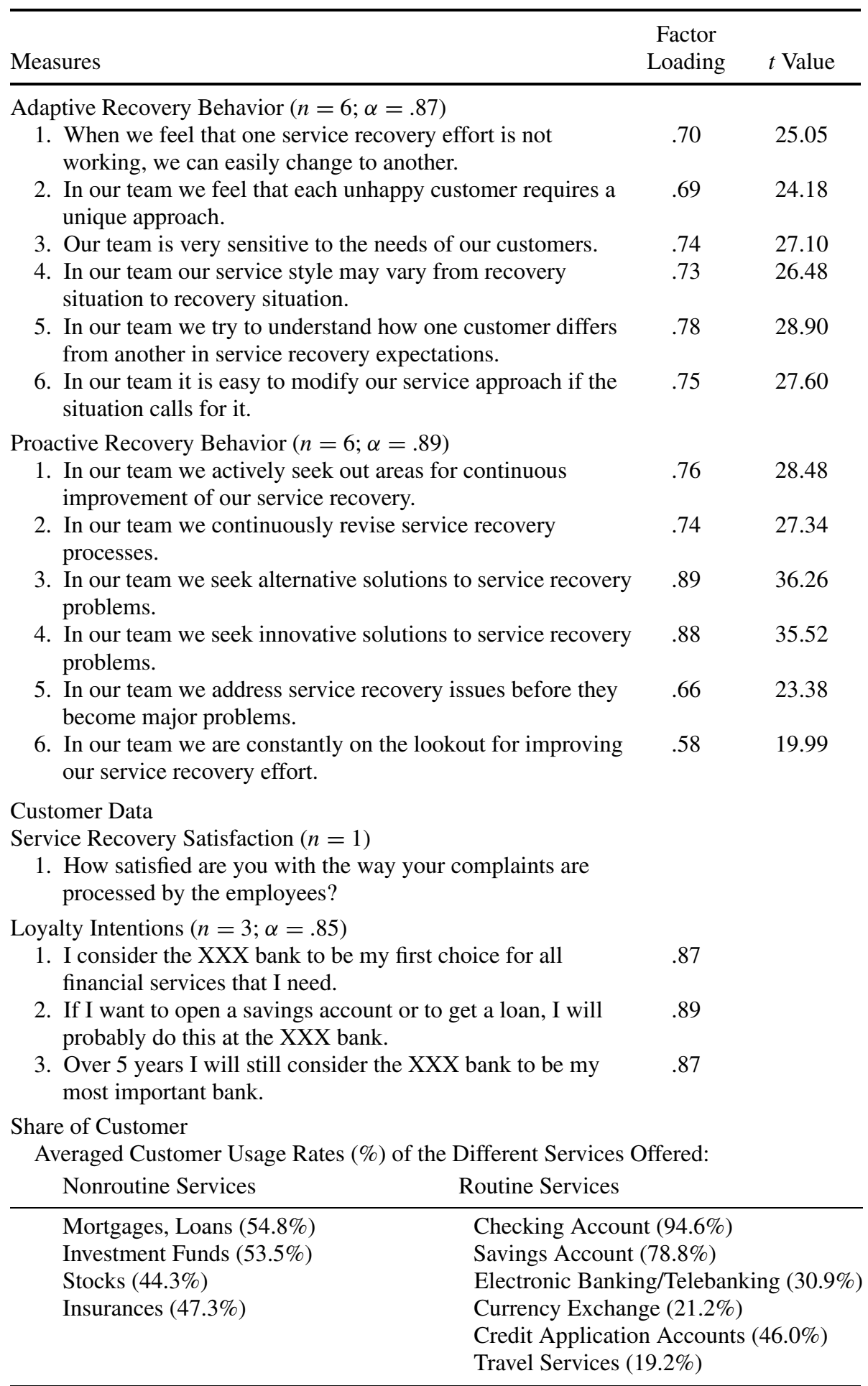

Note: All $t$ values are significant at $p<.05$. 
respondent behavior and decrease respondent reliability in service research (Drolet $\&$ Morrison, 2001). The measurement of loyalty intentions was based on items derived from the behavioral intentions battery of Zeithaml, Berry, and Parasuraman (1996) and involved a five-point scale, ranging from "strongly disagree" (1) to "strongly agree" (5). Principal component analysis showed construct validity (one factor was extracted with factor loadings for all items $\geq .87$ ). In addition, Cronbach's alpha is .85 , providing clear evidence of construct reliability. Second, customers were asked to indicate the different services they actually purchase in order to assess "share of customer" (this parameter reflects the average number of different services purchased per customer). An overview of the bank services offered in nonroutine and routine settings is presented in Table 2. Finally, the parameter "service revenues" was taken from the bank's internal database and reflects the work group's annual service revenues.

The assessment of the linkage between adaptive and proactive recovery behavior and their consequences involves aggregating team member perceptions as well as customer perceptions to the group level. This preference for the group as unit of analysis is based on previous studies (Allen \& Grisaffe, 2001; Meyer \& Allen, 1997). It has been argued that aggregate-level assessments of customer evaluations are needed, as customers observe the integral outcome of interpersonal working relationships among multiple employees (Allen \& Grisaffe, 2001). Furthermore, the out-group-homogeneity theory has postulated that people consider other groups as more uniform than their own group (Quattrone \& Jones, 1980). This suggests that individual customers are likely to consider the quality of service offered by one or multiple team members as a characteristic that inherently applies to the whole homogeneous out-group of employees. Furthermore, according to the social identity theory, people tend to perceive members of significant but antagonist out-groups in stereotypical (often negative) ways (Ashforth \& Mael, 1989). The fact that front-line workers operate at the opposite side of the service encounter, having to achieve financial performance goals that may conflict with the customers' interests (Singh, 2000), suggests that customers are likely to have stereotypical views of front-line team members. Finally, it is not possible to realize linkages between employee and customer parameters and productivity criteria at the individual level of analysis (Bryk \& Raudenbush, 1992). Therefore, individual employee and customer scores were aggregated to the group level of analysis and the linkage between service recovery behaviors and their consequences was tested using the team as the unit of analysis. As such, we did not account for individual differences within groups and analyzed the linkage between adaptive and proactive recovery behavior and its consequences at the group level.

Means, standard deviations, and individual-level and group-level correlations between the employee variables are presented in Table 3. It appears that scores on customer complaint management and interteam support are considerably lower when compared to the other work environment variables.

It has been argued that corrections for individual-level measurement error should be made first, before comparing individual- and aggregate-level correlations (Ostroff, 1993). Therefore, we used a procedure described by Nunnally and Bernstein (1994) to investigate what would happen with the individual-level correlations between the antecedents and recovery outcomes if we increased the 


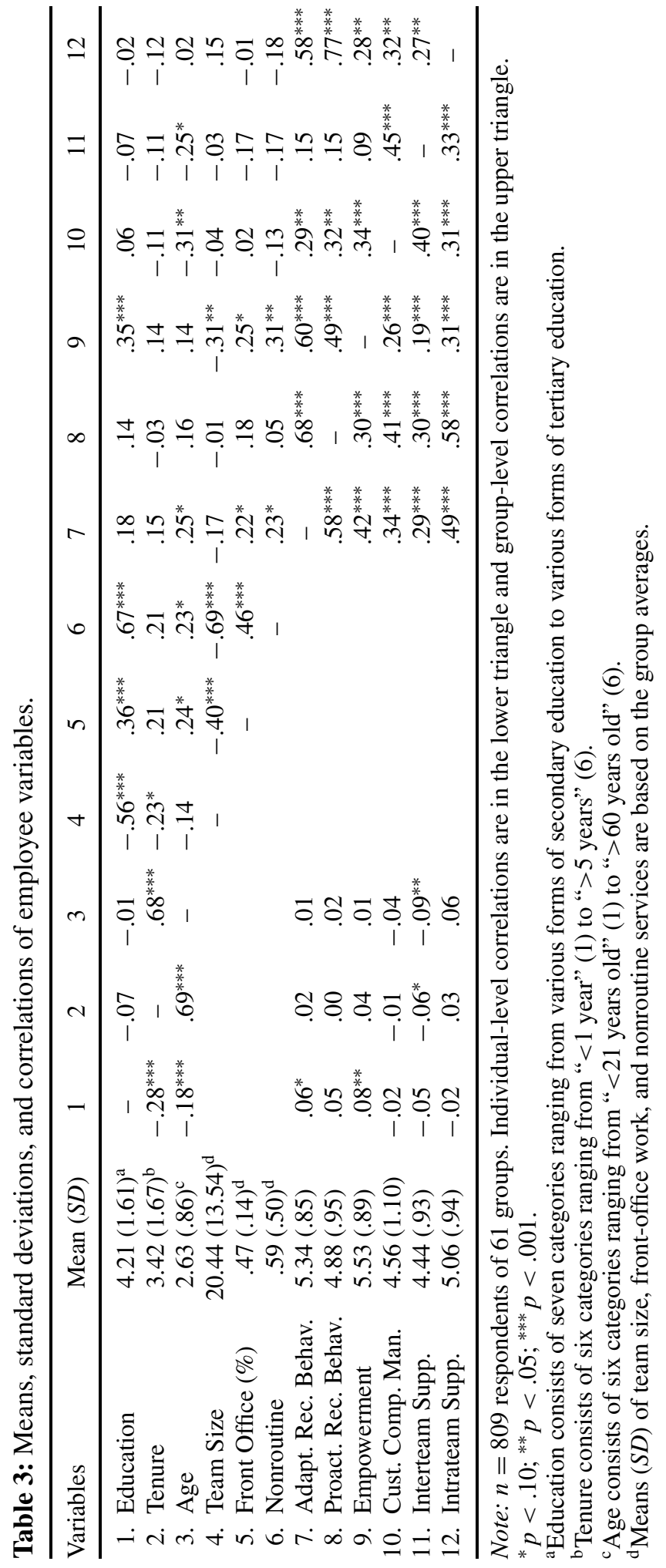


reliability of the constructs to .85 . Overall, the results indicate some increase of the individual-level correlations, but do not imply substantial changes in the magnitude differences between individual- and group-level correlations. Additionally, in Table 4, group-level means, standard deviations, and (partial) correlations of the employee variables and external outcome variables are represented.

We have calculated partial correlations among service recovery behavior and service outcomes, partialing out the effect of recovery satisfaction and global customer satisfaction, ${ }^{*}$ to check the notion that these variables mediate the relationships of proactive and adaptive recovery behavior with loyalty intentions and share of customer. The findings in Table 4 demonstrate that most correlations between the recovery behaviors and outcome variables show negligibly small changes after the effect of service recovery satisfaction or global customer satisfaction has been partialed out. Hence, these results do not confirm the mediating role of service recovery satisfaction and global customer satisfaction. Only the correlations of adaptive recovery behavior with loyalty intensions and share of customer appear to be noticeably weaker when the effect of service recovery satisfaction is accounted for, implying that service recovery satisfaction mediates the effect of adaptive recovery behavior on customer loyalty and share of customer (cf. Baron \& Kenny, 1986).

\section{Data Analysis and Results}

To justify aggregation of our employee data we calculated the average $r_{\mathrm{WG}(j)}$ coefficients and ICC (intraclass correlation) coefficients for adaptive recovery behavior, proactive recovery behavior, empowerment, customer complaint management, interteam support, and intrateam support. The results are reported in Table 5. The $r_{\mathrm{WG}(j)}$ coefficient concerns an indicator of within-group agreement. The $r_{\mathrm{WG}(j)}$ values are high for all variables (ranging from .83 to .96), indicating consistency in ratings among employees within groups (James, Demaree, \& Wolf, 1993). While the $r_{\mathrm{WG}(j)}$ exclusively considers differences among employee ratings within teams, the ICC (1) concerns a ratio of between-groups variance to total variance, taking within-group variance as well as the variance between groups into account. The ICC (1) values (ranging from .07 to .18) indicate that for all variables a moderate to considerable part concerns between-groups variance. To accurately determine the effect of interdependence, it is of importance to consider the group size. Therefore, we calculated ICC (2) coefficients, which also account for group size. All ICC (2) values are $\geq .50$, providing evidence for reliable group means, which permits the detection of aggregate-level relationships even in the case of quite small ICC (1) values (Bliese, 2000).

Additionally, the hypotheses H1-H6 were tested through a multivariate hierarchical linear model regression model, using MLwiN software (Rasbash et al., 2000). Three hierarchical levels are specified. Level 1 refers to the dependent variables indexed by $h=1, \ldots, m$, level 2 reflects the individual employees $i=$ $1, \ldots, n_{j}$, and level 3 involves the teams $j=1, \ldots, n$. As such, each assessment of a

\footnotetext{
*We have measured global customer satisfaction by asking customers to rate the following question “Overall, how satisfied are you with the XXX bank's service delivery?" Likewise recovery satisfaction, overall customer satisfaction was assessed by a five-point single-item scale ranging from "strongly dissatisfied" (1) to "strongly satisfied" (5).
} 


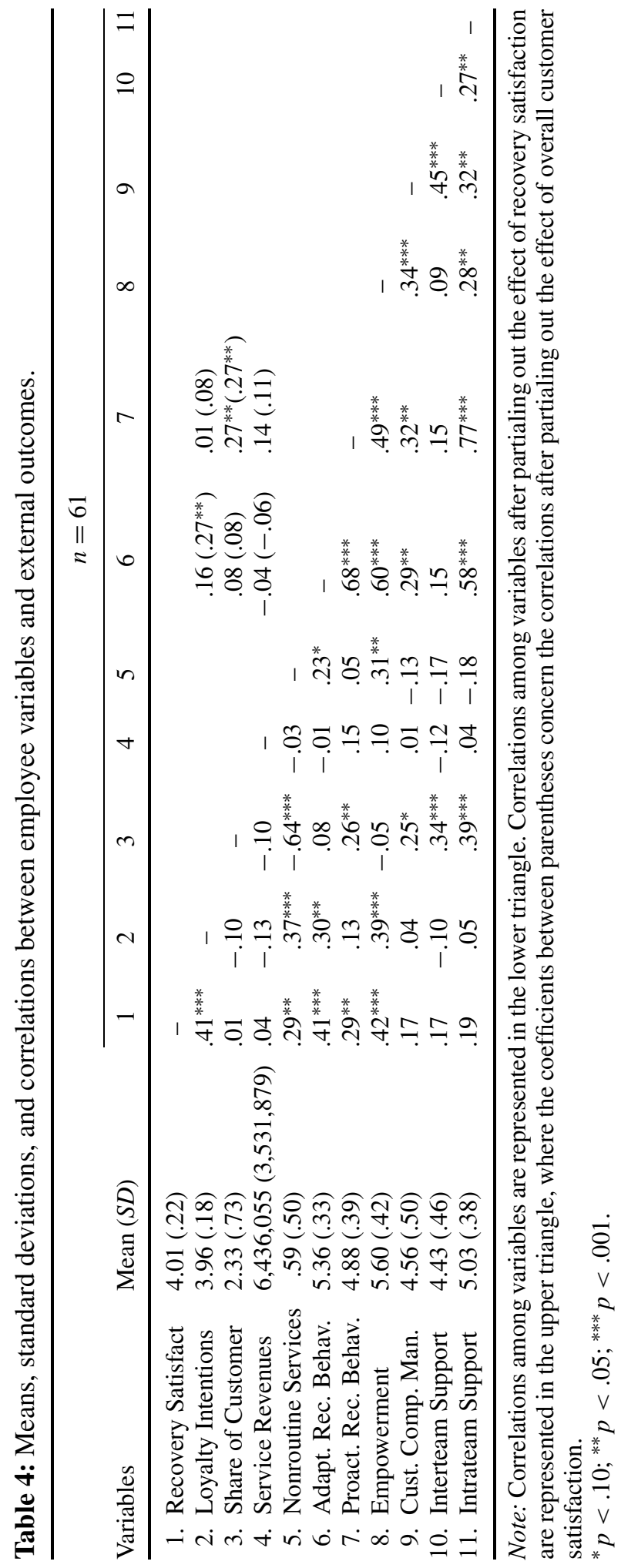


Table 5: Justification for aggregation measures.

\begin{tabular}{lccc}
\hline Variable & $\begin{array}{c}r_{\mathrm{WG}(j)} \\
\text { Coefficient }\end{array}$ & $\begin{array}{c}\text { ICC (1) } \\
\text { Coefficient }^{\mathrm{a}}\end{array}$ & $\begin{array}{c}\text { ICC (2) } \\
\text { Coefficient }^{\mathrm{a}}\end{array}$ \\
\hline Adaptive Recovery Behavior & .92 & .08 & .54 \\
Proactive Recovery Behavior & .94 & .09 & .57 \\
Empowerment & .96 & .16 & .72 \\
Customer Complaint Management & .84 & .15 & .70 \\
Interteam Support & .91 & .18 & .74 \\
Intrateam Support & .83 & .07 & .50 \\
\hline
\end{tabular}

${ }^{a}$ ICC (1) coefficients and ICC (2) coefficients are corrected for measurement error, which is defined as $(1-\alpha)$ (cf., Van Yperen \& Snijders, 2000).

given outcome variable on a certain team is indicated by a specific line in the data matrix, containing the values $i, j, h, Y_{h i j}, x_{1 i j}$, and all other predictors. To formulate the multivariate regression model as a hierarchical linear model, dummy variables $d_{1}$ to $d_{m}$ are used to indicate the outcome variables (i.e., adaptive recovery behavior, proactive recovery behavior). The dummy $d_{h}$ is 1 or 0 , depending on whether the data line refers to outcome variable $Y_{h}$ or to another outcome variable. This principle is expressed by the following equation:

$$
d_{s h i j}= \begin{cases}1 & h=s, \\ 0 & h \neq s .\end{cases}
$$

By means of these dummies, the regression equations for the $m$ outcome variables can be integrated into one three-level hierarchical model by the next expression:

$$
Y_{h i j}=\sum_{s=1}^{m} \gamma_{0 s} d_{s h i j}+\sum_{k=1}^{p} \sum_{s=1}^{m} \gamma_{k s} d_{s h i j} x_{k i j}+\sum_{s=1}^{m} u_{s j} d_{s h i j}+\sum_{s=1}^{m} e_{s i j} d_{s h i j} .
$$

All variables (including the constant) are multiplied by the dummy variables. With respect to the dummy variables, in the sums over $s=1, \ldots, m$, only the term $s=h$ renders a contribution, while all other terms are removed. For concreteness, we also represent the following regression equation, which is a simplified reformulation of equation (2):

$$
\begin{aligned}
Y_{h i j}= & \gamma_{00 h}+\gamma_{10 h} \mathrm{EDUC}_{i j}+\gamma_{20 h} \mathrm{TEN}_{i j}+\gamma_{30 h} \mathrm{AGE}_{i j}+\gamma_{40 h} \mathrm{EMP}_{i j} \\
& +\gamma_{50 h} \mathrm{COMPL}_{i j}+\gamma_{60 h} \mathrm{INTER}_{i j}+\gamma_{70 h} \mathrm{INTRA}_{i j}+\gamma_{01 h} \mathrm{EDUC}_{j} \\
& +\gamma_{02 h} \mathrm{TEN}_{j}+\gamma_{03 h} \mathrm{AGE}_{j}+\gamma_{04 h} \mathrm{SIZE}_{j}+\gamma_{05 h} \mathrm{FRONT}_{j} \\
& +\gamma_{06 h} \mathrm{NROUT}_{j}+\gamma_{07 h} \mathrm{EMP}_{j}+\gamma_{08 h} \mathrm{COMPL}_{j}+\gamma_{09 h} \mathrm{INTER}_{j} \\
& +\gamma_{010 h} \mathrm{INTRA}_{j}+u_{0 h j}+u_{1 h j}+u_{2 h j}+u_{3 h j}+u_{4 h j}+e_{h i j},
\end{aligned}
$$

where $Y_{h i j}$ is the measurement on the $h$ th variable for individual $i$ of group $j$; EDUC, TEN, and AGE, refer to the employee's education, tenure, and age, respectively; SIZE, FRONT, and NROUT are the size of the team, the percentage of front-office activities of the team, and the type of service setting in which the team operates, respectively; EMP, COMPL, INTER, and INTRA are empowerment, customer complaint management, interteam support, and intrateam support, respectively. 
In order to compare group-level and individual-level effects of the antecedents, the four antecedent variables were split into the group mean and the individual score of team members. The group-level coefficient was based on the group means, whereas the individual-level coefficient was based on the individual scores. For all four antecedents we specified individual-level and group-level coefficients, whereby the individual-level coefficients served as controls for the grouplevel ones (cf. Vancouver, Millsap, \& Peters, 1994). If the group-level coefficient of a certain antecedent remains significant after inclusion of its individual-level counterpart, this means that the group-level coefficient explains incremental variance in the outcome variable beyond the individual-level coefficient. Then, there exists an "independent" group-level effect of that particular antecedent on the outcome variable (Snijders \& Bosker, 1999).

First, we specified the covariance terms among the individual-level (level 2) and the group-level (level 3) variance components of adaptive and proactive recovery behavior (step 1). Second, the control variables were included in the model (step 2). Third, the individual scores of the four antecedent variables were added to the model (step 3). Finally, the group means of these antecedent variables were incorporated (step 4). Multilevel models concern contextual models that may be sensitive to multicollinearity. Therefore, regression analyses were performed to investigate multicollinearity by means of the Variance Inflation Factor (VIF). The VIFs of the control variables and the predictor variables are lower than 3.7 and 1.8, respectively. This indicates the absence of severe multicollinearity (Kleinbaum, Kupper, \& Muller, 1988). Table 6 provides the results of the multilevel analyses.

The specification of the covariance terms between adaptive and proactive recovery behavior leads to a significant increase in model fit (step 1), indicating significant linkages between both outcomes. In relation to the control variables, our findings show a positive effect of type of service setting on adaptive recovery behavior. Furthermore, there occurs a significant positive group-level effect of age, which appears significantly stronger in magnitude relative to the individuallevel effect of age. Finally, significant positive effects of the variables team size and percentage of front-office activities on proactive recovery behavior are found.

In testing hypotheses, our findings reveal significant positive individual-level effects of empowerment on adaptive and proactive recovery behavior, which means that $\mathrm{H} 1 \mathrm{a}$ and $\mathrm{H} 1 \mathrm{~b}$ are supported. Customer complaint management appears to be significantly positively related to both adaptive and proactive recovery behavior at the individual level. Thus, $\mathrm{H} 2 \mathrm{a}$ and $\mathrm{H} 2 \mathrm{~b}$ are supported. Positive effects of the individual-level coefficients of interteam support on both adaptive and proactive recovery behavior were found, which yields support for $\mathrm{H} 3 \mathrm{a}$ and $\mathrm{H} 3 \mathrm{~b}$. Subsequently, the significant positive individual-level effects of intrateam support on both types of recovery behavior indicate support for $\mathrm{H} 4 \mathrm{a}$ and $\mathrm{H} 4 \mathrm{~b}$. With regard to the crosslevel hypotheses, we find that only for intrateam support the magnitudes of the group-level coefficients are significantly greater when compared to individual-level ones. This means that H5a, H5b, H5c, H6a, H6b, and H6c can be rejected, while H5d and H6d are supported. Finally, the percentage of explained group-level variance is higher when compared to individual-level variance of both types of recovery 
Table 6: Multilevel analysis of antecedent-service recovery performance relationships.

\begin{tabular}{|c|c|c|}
\hline \multirow[b]{2}{*}{ Dependent Variables } & \multicolumn{2}{|c|}{ Antecedent Model } \\
\hline & $\begin{array}{l}\text { Adaptive Recovery } \\
\text { Behavior }(h=1) \\
\text { Coefficient }(\mathrm{SE})^{\mathrm{a}}\end{array}$ & $\begin{array}{c}\text { Proactive Recovery } \\
\text { Behavior }(h=2) \\
\text { Coefficient }(\mathrm{SE})^{\mathrm{a}}\end{array}$ \\
\hline Intercept & $.806(.946)$ & $-1.391(.953)$ \\
\hline Increase Model Fit ${ }^{\mathrm{b}}$ (step 1) & $\chi^{2}(2)=332.03^{* *}$ & \\
\hline $\begin{array}{l}\text { Control variables: level } 2 \\
\text { Education } \\
\text { Tenure } \\
\text { Age }\end{array}$ & $\begin{array}{r}.031(.025) \\
.012(.030) \\
-.036(.058)\end{array}$ & $\begin{array}{r}.029(.026) \\
.005(.032) \\
-.025(.061)\end{array}$ \\
\hline $\begin{array}{l}\text { Control variables: level } 3 \\
\text { Education } \\
\text { Tenure } \\
\text { Age } \\
\text { Team Size } \\
\text { Front Office }(\%) \\
\text { Nonroutine Services }\end{array}$ & $\begin{array}{r}-.075(.088) \\
-.054(.113) \\
.325(.218) \\
.000(.004) \\
-.311(.274) \\
.262(.141)^{*}\end{array}$ & $\begin{array}{c}.013(.090) \\
-.160(.114) \\
.401(.219)^{*} \\
.007(.004)^{*} \\
.534(.271)^{*} \\
.175(.142)\end{array}$ \\
\hline Increase Model Fit (Step 2) & $\chi^{2}(18)=18.56$ & \\
\hline $\begin{array}{l}\text { Antecedents: level } 2 \\
\text { Empowerment } \\
\text { Complaint Mgt. } \\
\text { Interteam Support } \\
\text { Intrateam Support }\end{array}$ & $\begin{array}{l}.228(.032)^{* *} \\
.129(.027)^{* *} \\
.095(.032)^{* *} \\
.287(.030)^{* *}\end{array}$ & $\begin{array}{l}.075(.034)^{*} \\
.223(.028)^{* *} \\
.076(.034)^{*} \\
.435(.032)^{* *}\end{array}$ \\
\hline Increase Model Fit (Step 3) & $\chi^{2}(16)=540.98^{* *}$ & \\
\hline $\begin{array}{l}\text { Antecedents: level } 3 \\
\text { Empowerment } \\
\text { Complaint Mgt. } \\
\text { Interteam Support } \\
\text { Intrateam Support }\end{array}$ & $\begin{array}{r}.064(.088) \\
-.048(.073) \\
-.125(.079) \\
.195(.094)^{*}\end{array}$ & $\begin{aligned} & .119(.089) \\
&-.140(.074)^{*} \\
&-.109(.080) \\
& .283(.095)^{* *}\end{aligned}$ \\
\hline Increase Model Fit (Step 4) & $\chi^{2}(8)=16.50^{*}$ & \\
\hline Residual Between-Groups Covariance Matrix ${ }^{\mathrm{c}}$ & 1. & 2. \\
\hline $\begin{array}{l}\text { 1. Adaptive Recov. Behavior } \\
\text { 2. Proactive Recov. Behavior }\end{array}$ & $\begin{array}{l}.009(.012) \\
.000(.000)\end{array}$ & $.000(.000)$ \\
\hline Residual Within-Group Covariance Matrix ${ }^{\mathrm{d}}$ & 1. & 2. \\
\hline $\begin{array}{l}\text { 1. Adaptive Recov. Behavior } \\
\text { 2. Proactive Recov. Behavior }\end{array}$ & $\begin{array}{l}.937(.048) \\
.343(.037)\end{array}$ & $1.033(.053)$ \\
\hline $\begin{array}{l}\text { Explained L-2 Variance }(\%) \\
\text { Explained L-3 Variance }(\%)\end{array}$ & $\begin{array}{l}36.8 \\
60.4\end{array}$ & $\begin{array}{l}44.2 \\
71.8\end{array}$ \\
\hline
\end{tabular}

Note: Significance of coefficients is based on one-tailed tests.

${ }^{*} p<.05 ;{ }^{* *} p<.01$.

${ }^{a}$ Unstandardized regression coefficients with standard errors in parentheses.

${ }^{b}$ Increase in model fit when specifying individual-level and group-level relationships between the dependent variables.

${ }^{\mathrm{c}} \operatorname{var}\left(u_{h j}\right)=\tau_{h h}$ and $\operatorname{cov}\left(u_{h j}, u_{h^{\prime} j}\right)=\tau_{h h^{\prime}}$.

$\mathrm{d}_{\operatorname{var}}\left(e_{h i j}\right)=\sigma_{h h}$ and $\operatorname{cov}\left(e_{h i j}, e_{h^{\prime} i j}\right)=e_{h h^{\prime}}$. 
behavior. This signifies that the antecedents better explain between-groups differences than within-group differences of both dependent variables.

Next, we test the hypotheses $\mathrm{H} 7-\mathrm{H} 10$ by estimating a multivariate two-level regression model. Level 1 refers to the dependent variables indicated as $h=1, \ldots, m$ and level 2 reflects the teams $j=1, \ldots, n$. Hence, each measurement of a dependent variable on some group is represented by a separate line in the data matrix, including the values, $j, h, Y_{h j}, x_{1 j}$, and those of the other explanatory variables. To formulate the multivariate regression model as a hierarchical linear model, dummy variables $d_{1}$ to $d_{m}$ are specified to indicate the dependent variables (i.e., service recovery satisfaction, loyalty intentions, share of customer, service revenues). Dummy variable $d_{h}$ is 1 or 0 , depending on whether the data line refers to the dependent variable $Y_{h}$ or another dependent variable. By means of these dummies, the regression models for the $m$ dependent variables can be integrated into one two-level hierarchical model by the following equation:

$$
Y_{h j}=\sum_{s=1}^{m} \gamma_{0 s} d_{s h j}+\sum_{k=1}^{p} \sum_{s=1}^{m} \gamma_{k s} d_{s h j} x_{k j}+\sum_{s=1}^{m} e_{s j} d_{s h j} .
$$

All variables (also the constant) are multiplied by the dummy variables. Note that the definition of the dummy variables implies that in the sums over $s=1, \ldots, m$ only the term for $s=h$ gives a contribution, while all other terms are removed. The next model equation involves a simplified version of equation (4):

$$
Y_{h j}=\gamma_{0 h}+\gamma_{1 h} \mathrm{NROUT}_{j}+\gamma_{2 h} \mathrm{ADAP}_{j}+\gamma_{3 h} \mathrm{PRO}_{j}+e_{h j}
$$

where $Y_{h j}$ is the measurement on the $h$ th variable for group $j$; NROUT refers to the type of service setting in which the team functions; ADAP and PRO indicate the team's level of adaptive and proactive recovery behavior, respectively.

We used the following analysis strategy to test the hypotheses H7-H10. First, the "nonroutine" dummy was included (step 1). Second, the adaptive and proactive recovery behavior variables were added to the model (step 2). To account for multicollinearity we inspected the VIFs of the predictor variables, which all show VIF values below 2.1, indicating that there is no serious multicollinearity. Our results are presented in Table 7 and show significant positive effects of adaptive recovery behavior on service recovery satisfaction and loyalty intentions supporting $\mathrm{H} 7 \mathrm{a}$ and H8a, respectively. In contrast, proactive recovery behavior is not significantly related to service recovery satisfaction and loyalty intentions, which implies that $\mathrm{H} 7 \mathrm{~b}$ and $\mathrm{H} 8 \mathrm{~b}$ are rejected. Next, there exist no significant linkages between adaptive recovery behavior and share of customer or service revenues. Thus, H9a and H10a have to be rejected. Additionally, proactive recovery behavior appears to have a positive effect on share of customer, while it is not significantly related to the service revenues, indicating support for H9b, whereas H10b is rejected. Finally, there occur significant positive effects of nonroutine services on service recovery satisfaction and loyalty intentions, while the dummy is negatively related to share of customer. 


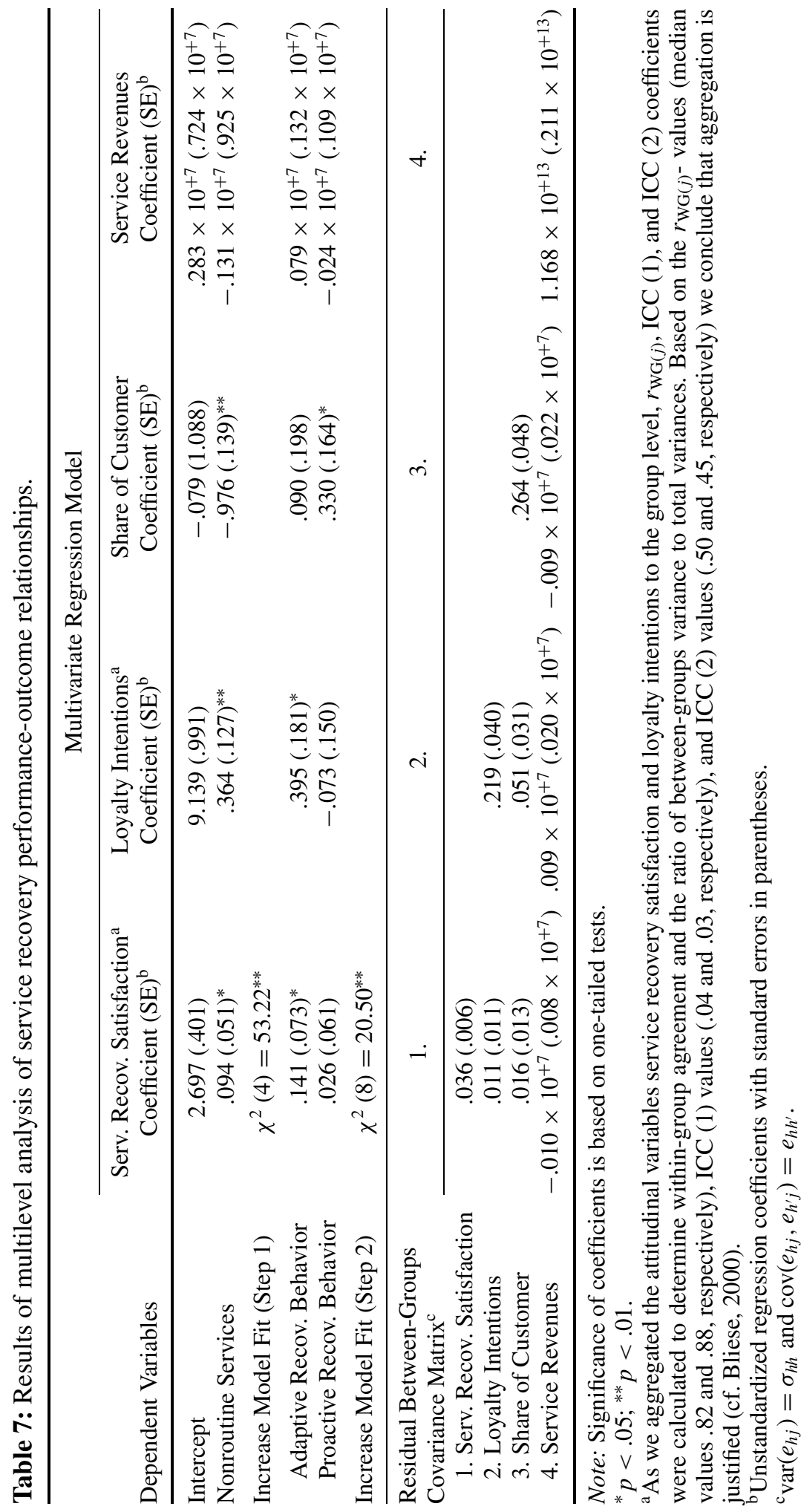




\section{DISCUSSION}

The aim of this study is to extend our understanding of service recovery behavior by members of front-line service SMTs and to empirically assess the impact of antecedents and consequences of this behavior. Overall, the antecedent-recovery behavior relationships show remarkable consistency across the two types of service recovery behavior. Specifically, our findings show positive individual-level effects of empowerment, customer complaint management, interteam support, and intrateam support on adaptive as well as proactive recovery behavior, providing support for the individual-level hypotheses. To begin with, these findings imply that differences in individual employees' cognitions and interpretations of the work environment determine adaptive and proactive recovery behavioral practice in SMTs. A supportive organizational context that encourages autonomous decision making and recognizes the importance of systematically identifying and managing complaints, promotes service recovery as a team effort and may prevent individual employees from employing isolated and idiosyncratic problem solving and developing "proprietary" knowledge (Sarin \& McDermott, 2003; Teigland \& McLure Wasko, 2003). Moreover, by fostering opportunities for cross-functional knowledge exchange within and between SMTs, tacit service recovery knowledge may be turned into explicit knowledge that is shared within and between SMTs.

In order to provide a more ecologically accurate description of the contextual influences on recovery behaviors, our study adopted an approach that analyzes the influence of predictor variables at two levels. Group-level effects represent consensual beliefs, which refer to the fact that individual members come to share their interpretation with other members in the team. We find an independent group-level effect of intrateam support, which explains additional variance of adaptive and recovery behavior beyond the individual-level effect. This means that standards of helping behavior that are developed within the context of the team govern the behavior of the individual members. As recent meta-analytic research on teams by Stewart (2000) has shown, particularly intrateam processes are influential in determining the effectiveness of work units. Our results are also in line with previous team research in service settings (Mohammed, Matthieu, \& Bartlett, 2002) that suggests that perceptual consensus among employees within a team on extra-role behavior may be relevant to decisions pertaining to the team's core tasks. The more team members support each other in the collective decision-making process within the team, the greater the ability to take adaptive and proactive decisions together. Supportive intrateam behavior by team members helps them to acquire a good overview of their recovery activities, improving the flow of information about the inputs, limitations, and solutions in their problem-solving process. Hence, team member cooperation forms a necessary ingredient to effectively adapt work routines efficiently after important service failures or to anticipate on the need for change by implementing service innovations.

Team effectiveness may also depend on background characteristics and how team demographics are combined (Hackman, 1992). We find an independent positive group-level effect of age that explains variance in proactive recovery behavior 
beyond the individual-level effect of age. This signifies that SMTs with a relatively high average for age are likely to display more proactive behavior. The positive group-level effect of age on proactive recovery behavior may be due to the fact that employees become more experienced over time in identifying customer problems and possess better social skills in actively dealing with them (cf. Martocchio, 1989). At the group level proactive behavior is also positively influenced by team size and the degree of front-office work that the SMT performs. In addition, it appears that SMTs that deliver more complex or nonroutine services are likely to display adaptive behavior. Nonroutine services are associated with intensive, personalized employee-customer encounters, which urgently require listening skills and empathy toward customers' viewpoints and opinions as prerequisites for employees to properly alter their service approach (Anderson et al., 1997). In general, our study demonstrates the merit of considering multiple analyses when investigating performance and substantiates findings of earlier organizational research (Vancouver et al., 1994).

We also investigated the effects of adaptive and proactive recovery behavior on service performance parameters. Our findings show that an adaptive recovery approach has a positive effect on customer-based performance measures. It appears that a higher degree of adaptive behavior leads to improvements in service recovery satisfaction and loyalty intentions. Apparently, the adaptive, personalized, and creative way in which front-line employees manage service problems is highly valued by customers and strengthens their repurchase intentions. Contrary to our expectations, adaptive recovery behavior is not related to share of customer or service revenues. The absence of a relationship between adaptive recovery behavior and share of customer corresponds with previous research on sales performance by Spiro and Weitz (1990), who did not find a conclusive relationship between adaptive selling and sales performance.

In contrast, the impact of proactive recovery behavior becomes apparent in relation to actual customer behavior, as it leads to higher share of customer rates. Higher levels of proactive recovery servicing enhance the average number of different services sold per customer. Members of highly proactive teams initiate more efforts to employ extra resources to deliver additional services and are better able to utilize the market opportunities. This is in line with a recent study on proactive behavior in a sales setting that demonstrates a positive impact of proactive behavior on sales force performance (Pitt et al., 2002). However, proactive recovery behavior is not related to service revenues. This discrepancy in findings may be attributed to the differential nature of these measures. The share of customer criterion typically concerns a customer behavioral measure, which rationale concerns maximization of the relationship with each individual customer. Conversely, traditional productivity measures do not take such a customer relationship perspective, focusing primarily on input-output convergence. These diverging results confirm that there exists a paradox between customer-based and productivity-based performance measures in services. Anderson et al. (1997) contend that trade-offs between different performance parameters are more probable in services and emphasize the necessity to set off customer parameters against productivity parameters in order to create an optimal balance. 


\section{LIMITATIONS AND THEORETICAL IMPLICATIONS}

Our findings have a number of implications for theory development and future research. To begin with, while our findings indicate that adaptive and proactive recovery behaviors share the same antecedents, these antecedents considerably better explain proactive behavior. This suggests that, although adaptive and proactive recovery behaviors appear to have common roots, there may be subtle but relevant differences in their conceptual foundation. Future research should incorporate additional antecedents to better explain adaptive recovery behavior.

Furthermore, the differential influences of adaptive and proactive recovery behavior on external service recovery outcomes suggest the relevance of discerning distinctive components of service recovery performance when investigating internal and external marketing performance linkages in future marketing research. In addition, the substantially high intercorrelations among the predictor variables may have influenced the results. For example, the effect of proactive recovery behavior on service recovery satisfaction is nonsignificant, while the pair-wise correlation is substantial and significant. To allow for generalizations of the differential consequences of adaptive versus proactive recovery behaviors, additional comparative research on these and more distinct extra-role servicing behaviors is required in other services sectors (e.g., tourist industry, restaurant industry, automobile industry). Services clearly differ in nature, ranging from relatively standardized repetitive activities to customer-intensive complex knowledge work. Therefore, in order to account for these variations, a contingency approach is required when investigating service recovery performance of empowered work teams (cf. Bowen \& Lawler, 1992).

In testing the relationships between antecedents and adaptive and proactive recovery behaviors, different levels of analysis were considered. Employee scores were aggregated at the group level to compare consistency of relationships across levels. An essential limitation concerns common method variance (CMV), which may have biased the relationships that were estimated between both outcome variables and its antecedents. We addressed this issue, using the approach of Lindell and Whitney (2001). According to Lindell and Brandt (2000) and Lindell and Whitney (2001) the smallest correlation among manifest variables provides a reasonable proxy for CMV. This smallest correlation $\left(r_{s}\right)$ needs to be partialed out of the remaining correlations in order to remove the effect of CMV. In general, based on the fact that all unadjusted correlation coefficients remain statistically significant at the $.05 p$-level after adjusting for CMV, we conclude that the results that we found in our analysis are not due to CMV. Further research in this matter is warranted.

Additionally, our results reveal that most antecedent-performance relationships operate at the individual level of analysis. However, there occurs an independent group-level effect of intrateam, which accounts for additional variance in the recovery variables beyond the individual-level effect. Additional research is required to address the rationale behind these levels-of-analysis differences. Although recent multilevel theory and research has been increasingly applied and a number of studies empirically address levels-of-analysis comparisons, theorygrounded hypotheses still need further development (Ostroff, Kinicki, \& Clark, 
2002; Ostroff \& Harrison, 1999; Van Yperen \& Snijders, 2000; Vancouver et al., 1994).

Furthermore, failure or problem severity has been recognized as an important issue in the area of service recovery. For instance, Miller, Craighead, and Karwan (2000) demonstrate that serious recovery problems have less chance to be resolved. Other studies have shown that failure severity has a negative impact on customers' service recovery expectations (e.g., Maxham \& Netemeyer, 2002). One intriguing implication is the extent to which failure severity moderates relationships with service recovery performance, as well as relationships with customer outcome measures. Are the relationships found in this article consistent over varying magnitudes of service failures? We recommend future recovery studies to investigate the moderating role of service failure severity in relation to the service recovery performance of SMTs.

Finally, in this study we have investigated the impact of customer serviceoriented recovery behaviors. To obtain a more balanced perspective future theoretical frameworks need also to incorporate productivity-oriented recovery behaviors. A simultaneous investigation of both service-oriented and productivity-oriented recovery behaviors allows for a better understanding of the emerging discrepancies between customer-based and traditional productivity-based performance goals (cf. Singh, 2000).

\section{MANAGERIAL IMPLICATIONS}

Our findings have a number of implications for managerial decision making. First, the differential impact of adaptive and proactive recovery behaviors on external performance parameters suggests that managers need to consider adaptability and proactivity as complementary, but distinctive components of service recovery performance. Accordingly, in decisions about service personnel selection criteria and recovery training programs, a clear distinction should be made between adaptive recovery behaviors, such as listening skills and problem analysis protocols, and proactive behaviors, such as taking initiative to change failure-prone service routines. One effective way to train employees in both types of behaviors is to develop training scenarios that expose employees to simulated real-life situations that require them to make decisions related to adaptive and/or proactive performance.

The instruments used in our research provide a framework for diagnosing and deciding what types of behavior are required in the field of service recovery.

Second, as self-management involves delegating decisional authority to the front-line, employees should be stimulated to exercise improvisation skills, decision making, and innovative problem solving. They should also be given the necessary resources to support service recovery decision making. For example, the implementation of shared databases to achieve an updated registration of essential customer and product information, service failure incidents, and employees' recovery actions may be an effective strategy to sustain employees' recovery efforts. Internal service policies aimed at a service-oriented attitude are also crucial to improve cooperation among employees within and between teams. The relevance 
of such a pro-social attitude could be emphasized in monthly organizational meetings, recognition programs and success cases, as well as selection procedures, for instance, by employing tests for applicants' service-oriented value orientation and interpersonal skills.

Third, management action may be taken to encourage decision making within the team. Given the group-level impact of intrateam support, team-level interventions may encourage employees' commitment to the team-based decision-making process, stimulating them to discuss innovative solutions and to actively cooperate as members of the team. The supportive intrateam processes by which group member interact can influence the quality of decision making; a structured, constructive, direct debate can help group members to identify various alternatives and make appropriate service recovery decisions. Such interventions include group training intended to improve interpersonal process among team members, like communication, coordination, cooperation, information sharing with one another and learning how to use this information to make proper judgments and recommendations about occurring service recovery problems. By offering SMTs the opportunity to develop interdependent decision aids, constructive discussion on adaptive and proactive service recovery strategies may be stimulated. Following this logic, it is relevant to explicitly relate team decision-making performance to the team's ability to adjust its functional structure after an unexpected problem or to actively anticipate problems that are to be expected in the future. Furthermore, the implementation of team-based rewards systems could also be considered as a means to stimulate supportive decision-making processes among team members within the SMT.

Finally, the differential effects of adaptive and proactive recovery behaviors on external performance parameters suggest that excellence in service recovery requires different decisions that complement each other, such as empathizing and apologizing actions, as well as providing fair compensation for the costs or preventively restructuring service routines. The absence of any relationship of adaptive and proactive recovery skills with service revenues implies that exclusively aiming at customer service-oriented recovery skills might lead to a one-sided attention of customer-based parameters, which goes at the expense of the SMT's productivity. This implies that companies may need to decide to strike a balance between customer-based and productivity goals in developing their service recovery strategy. Besides extra-role recovery efforts intended to resolve diversified customer requests adequately, it is also relevant to keep an eye on low-cost and efficiency-based recovery procedures. To save time and labor costs it may be worthwhile to employ standard recovery modes in relation to customer complaints that are comparatively routine and uncomplicated in nature. Since information technology-based service delivery combines a customized service approach with the advantages of standardization, the implementation of information technology-based recovery procedures should be considered as a valuable alternative. All in all, in making decisions related to a service recovery strategy, managers should recognize that effective service recovery requires differential behavioral skills and that it is important to take into account the impact of interpersonal processes. [Received: December 2002. Accepted: February 2004.] 


\section{REFERENCES}

Allen, N. J., \& Grisaffe, D. B. (2001). Employee commitment to the organization and customer reactions: Mapping the linkages. Human Resource Management Review, 11, 209-236.

Anderson, E. W., Fornell, C., \& Rust, R. T. (1997). Customer satisfaction, productivity, and profitability: Differences between goods and services. Marketing Science, 16(2), 129-145.

Anderson, J. C., \& Gerbing, D. W. (1988). Structural equation modeling in practice: A review and recommended two-step approach. Psychological Bulletin, 103(1), 411-423.

Andrews, K. Z. (1995). Cross-functional teams. Harvard Business Review, 73(6), $12-13$.

Armistead, C. G., \& Clark, G. (1994). Service quality and service recovery: The role of capacity management. In G. Weary, F. Gleicher, \& K. L. Marsh (Eds.), Control motivation and social cognition. New York: Springer-Verlag, 33-73.

Armstrong, J. S., \& Overton, T. S. (1977). Estimating nonresponse bias in mail surveys. Journal of Marketing Research, 14, 396-402.

Ashforth, B. E., \& Mael, F. (1989). Social identity theory and the organization. Academy of Management Review, 14(1), 20-39.

Aspinwall, L. G., \& Taylor, S. E. (1997). A stitch in time: Self-regulation and proactive coping. Psychological Bulletin, 121(3), 417-436.

Babin, B. J., \& Attaway, J. A. (2000). Atmospheric affect as a tool for creating value and gaining share of customer. Journal of Business Research, 49(2), 91-100.

Bandura, A. (1986). Social foundations of thought and action: A social cognitive theory. Englewood Cliffs, NJ: Prentice Hall.

Bansal, H. S., Mendelson, M. B., \& Sharma, B. (2001). The impact of internal marketing activities on external marketing outcomes. Journal of Quality Management, 6, 61-76.

Baron, R. M., \& Kenny, D. A. (1986). The moderator-mediator variable distinction in social psychological research: Conceptual, strategic, and statistical considerations. Journal of Personality and Social Psychology, 51(6), 1173-1182.

Bartel, C. A., \& Saavedra, R. (2000). The collective construction of work group moods. Administrative Science Quarterly, 45(2), 197-231.

Bateman, T. S., \& Crant, M. J. (1993). The proactive component of organizational behavior. Journal of Organizational Behavior, 14(2), 103-118.

Bateman, T. S., \& Crant, M. J. (1999). Proactive behavior: meaning, impact, recommendations. Business Horizons, 42(3), 63-70.

Batt, R. (1999). Work organization, technology and performance in customer service and sales. Industrial and Labor Relations Review, 52(4), 539-563. 
Bell, C. R., \& Zemke, R. E. (1987). Service breakdown: The road to recovery. Management Review, 76(10), 32-35.

Bitner, M. J. (1990). Evaluating service encounters: The effects of physical surroundings and employee responses. Journal of Marketing, 54(2), 69-82.

Bitner, M. J., Booms, B. H., \& Mohr, L. A. (1994). Critical service encounters: The employee's viewpoint. Journal of Marketing, 58(4), 95-106.

Bitner, M. J., Booms, B. H., \& Tetreault, M. S. (1990). The service encounter: Diagnosing favorable and unfavorable incidents. Journal of Marketing, 54(1), 69-82.

Blau, G. (1995). Influence of group lateness on individual lateness: A cross-level examination. Academy of Management Journal, 38(5), 1483-1496.

Bliese, P. D. (2000). Within-group agreement, non-independence, and reliability: Implications for data aggregation and analysis. In K. J. Klein \& S. W. J. Kozlowski (Eds.), Multilevel theory, research, and methods in organizations. San Francisco: Jossey-Bass, 349-381.

Boshoff, C. (1999). RECOVSAT: An instrument to measure satisfaction with transaction-specific service recovery. Journal of Service Research, 1(3), 236249.

Boshoff, C., \& Allen, J. (2000). The influence of selected antecedents on frontline staff's perceptions of service recovery performance. International Journal of Service Industry Management, 11(1), 63-90.

Boshoff, C., \& Leong, J. (1998). Empowerment, attribution and apologising as dimensions of service recovery: An experimental study. International Journal of Service Industry Management, 9(1), 24-47.

Bowen, D. E., \& Johnston, R. (1999). Internal service recovery: Developing a new construct. International Journal of Service Industry Management, 10(2), $118-131$.

Bowen, D. E., \& Lawler III, E. E. (1992). The empowerment of service workers: What, why, how, and when. Sloan Management Review, 33(Spring), 31-39.

Bowen, D. E., \& Lawler III, E. E., (1995a). Empowering service employees. Sloan Management Review, 36(Summer), 73-84.

Bowen, D. E., \& Lawler III, E. E. (1995b). Organizing for service: Empowerment or production line? In W. J. Glynn \& J. G. Barnes (Eds.), Understanding services management. Chichester, England: John Wiley \& Sons, 269-294.

Bryk, A. S., \& Raudenbush, S. W. (1992). Hierarchical linear models: Applications and data analysis methods. Newbury Park, CA: Sage.

Campion, M. A., Medsker, G. J., \& Higgs, C. A. (1993). Relations between work group characteristics and effectiveness: Implications for designing effective work teams. Personnel Psychology, 46(4), 823-850.

Chebat, J. C., \& Kollias, P. (2000). The impact of empowerment on customer contact employees' roles in service organizations. Journal of Service Research, 3(1), 217-229. 
Cook, J. D., Hepworth, S. J., Wall, T. D., \& Warr, P. B. (1981). The Experience of work: A compendium and review of 249 measures and their use. London: Academic Press.

Crant, J. M. (1995). The proactive personality scale and objective job performance among real estate agents. Journal of Applied Psychology, 80(4), 532-537.

Crant, J. M. (2000). Proactive behavior in organizations. Journal of Management, 26(3), 435-462.

Drolet, A. L., \& Morrison, D. G. (2001). Do we really need multiple-item measures in service research? Journal of Service Research, 3(3), 196-204.

Emery, C. R., \& Fredenhall, L. D. (2002). The effect of teams on firm profitability and customer satisfaction. Journal of Service Research, 4(3), 217-229.

Festinger, L. (1954). A theory of social comparison processes. Human Relations, 7, 117-140.

Hackman, J. R. (1992). Group influences on individuals in organizations. In M. D. Dunnette \& L. M. Hough (Eds.), Handbook of industrial \& organizational psychology. Palo Alto, CA: Consulting Psychologists Press, 199-267.

Halstead, D., Droge, C., \& Cooper, M. B. (1993). Product warranties and postpurchase service: A model of consumer satisfaction with complaint resolution. Journal of Service Marketing, 7(1), 33-40.

Hart, C. W. L., Heskett, J. L., \& Sasser, W. E. (1990). The profitable art of service recovery. Harvard Business Review, 69(4), 148-156.

Hartline, M. D., \& Ferrell, O. C. (1996). The management of customer-contact service employees: An empirical investigation. Journal of Marketing, 60(4), $52-70$.

Hatano, G., \& Inagaki, K. (1986). Two sources of expertise. In H. Stevenson, H. Azuma, \& K. Hakuta (Eds.), Child development and education in Japan. New York: W. H. Freeman, 262-272.

Helfert, G., \& Vith, K. (1999). Relationship marketing teams: Improving the utilization of customer relationships potentials through a high team design quality. Industrial Marketing Management, 28(5), 553-564.

Heskett, J. L., Sasser, W. E., \& Schlesinger, L. A. (1997). The service profit chain. New York: Free Press.

Hocutt, M. A., \& Stone, T. H. (1998). The impact of employee empowerment on the quality of a service recovery effort. Journal of Quality Management, 3(1), $117-132$.

Holyoak, K. J. (1991). Symbolic connectionism: Toward third-generation theories of expertise. In K. A. Ericsson \& J. Smith (Eds.). Toward a general theory of expertise. Cambridge, England: Cambridge University Press, 301335.

Houston, M. B., Walker, B. A., Hutt, M. D., \& Reingen, P. H. (2001). Cross-unit competition for a market charter: The enduring influence of structure. Journal of Marketing, 65(2), 19-34. 
Humphrey, R. H., \& Ashforth, B. E. (1994). Cognitive scripts and prototypes in service encounters. In T. A. Swartz, D. E. Bowen, \& S. W. Brown (Eds.), Advances in service marketing and management. Vol. 3, Greenwich, CT: JAI Press, 175-199.

Hyatt, D. E., \& Ruddy, T. M. (1997). An examination of the relationship between work group characteristics and performance: Once more into the breech. Personnel Psychology, 50(3), 553-585.

Iacobucci, D. (1998). Services: What do we know and where shall we go? A view from marketing. In T. A. Swartz, D. E. Bowen, \& S. W. Brown (Eds.), Advances in service marketing and management. Greenwich, CT: JAI Press, Vol. 7, 1-96.

James, L. R., Demaree, R. G., \& Wolf, G. (1993). An assessment of withingroup interrater agreement. Journal of Applied Psychology, 78(2), 306309.

Johnston, R. (1995). Service failure and recovery: Impact, attributes, and process. Advances in Service Marketing and Management: Research and Practice, 4, 211-228.

Jöreskog, K. G., \& Sörbom, D. (1993). LISREL 8: A guide to the program and applications. Chicago: SPSS.

Kidwell, E. R., Jr., \& Mossholder, K. W. (1997). Cohesiveness and organizational citizenship behavior: A multilevel analysis using work teams and individuals. Journal of Management, 23(6), 775-793.

Kirkman, B. L., \& Rosen, B. (1999). Beyond self-management: Antecedents and consequences of team empowerment. Academy of Management Journal, $42(1), 58-74$.

Kleinbaum, D. G., Kupper, L. L., \& Muller, K. E. (1988). Applied regression analysis and other multivariable methods (2nd ed.). Boston: PWS-KENT.

Lawler, E. E. (1986). High-involvement management: Participative strategies for improving organisational performance. San Francisco: Jossey Bass.

Ledford, G. E. (1993). Employee involvement: Lessons and predictions. In J. R. Galbraith \& E. E. Lawler (Eds.), Organizing for the future. San Francisco: Jossey-Bass, 43-64.

Lindell, M. K., \& Brandt, C. J. (2000). Climate quality and climate consensus as mediators of the relationship between organizational antecedents and outcomes. Journal of Applied Psychology, 85(3), 331-348.

Lindell, M. K., \& Whitney, D. J. (2001). Accounting for common method variance in cross-sectional research designs. Journal of Applied Psychology, 86(1), $114-121$

London, M., \& Mone, E. M. (1999). Continuous learning. In D. R. Ilgen \& E. D. Pulakos (Eds.), The changing nature of performance: Implications for staffing, motivation, and development. San Francisco: Jossey-Bass, 119153. 
Mathieu, J., \& Kohler, S. (1990). A cross-level examination of group absence influence on individual absence. Journal of Applied Psychology, 75(2), 217220.

Martocchio, J. (1989). Age-related differences in employee absenteeism: A metaanalysis. Psychology and Aging, 4, 409-414.

Maxham, J. G., III, \& Netemeyer, R. G. (2002). A longitudinal study of complaining customers' evaluations of multiple service failures and recovery efforts. Journal of Marketing, 66(October), 57-71.

Meyer, J. P., \& Allen, N. J. (1997). Commitment to the workplace: Theory, research, and application. Thousand Oaks, CA: Sage.

Miller, J. L., Craighead, C. W., \& Karwan, K. R. (2000). Service recovery: A framework and empirical investigation. Journal of Operations Management, $18,387-400$.

Mohammed, S., Mathieu, J. E., \& Bartlett, A. L. (2002). Technical-administrative task performance, leadership performance and contextual performance: Considering the influence of team- and task-related composition variables. Journal of Organizational Behavior, 23, 795-814.

Morrison, E. W., \& Phelps, C. C. (1999). Taking charge at work: Extrarole efforts to initiate workplace change. Academy of Management Journal, 42(4), 403419.

Mulaik, S. A., James, L. R., Van Alstine, J., Bennett, N., Lind, S., \& Stilwell, C. (1989). Evaluation of goodness-of-fit indices for structural equation models. Psychological Bulletin, 105(3), 430-445.

Neuman, G. A., \& Wright, J. (1999). Team effectiveness: Beyond skills and cognitive ability. Journal of Applied Social Psychology, 29(6), 376-389.

Nunnally, J. C., \& Bernstein, I. H. (1994). Psychometric theory (3rd ed.). New York: McGraw-Hill.

Ostroff, C. (1993). Comparing correlations based on individual-level and aggregated data. Journal of Applied Psychology, 78(4), 569-582.

Ostroff, C., \& Harrison, D. A. (1999). Meta-level of analysis, and best estimates of population correlations: Cautions for interpreting meta-analytic results in organizational behavior. Journal of Applied Psychology, 84(2), 260270 .

Ostroff, C., Kinicki, A. J., \& Clark, M. A. (2002). Substantive and operational issues of response bias across levels of analysis: An example of climate-satisfaction relationships. Journal of Applied Psychology, 87(2), 355-368.

Peccei, R., \& Rosenthal, P. (1997). The antecedents of employee commitment to customer service: Evidence from a UK service context. The International Journal of Human Resource Management, 8(1), 66-86.

Peccei, R., \& Rosenthal, P. (2001). Delivering customer-oriented behaviour through empowerment: An empirical test of HRM assumptions. Journal of Management Studies, 38(6), 831-857. 
Pitt, L. F., Ewing, M. T., \& Berthon, P. R. (2002). Proactive behavior and industrial salesforce performance. Industrial Marketing Management, 31, 639644.

Pulakos, E. D., Arad, S., Donovan, M. A., \& Plamondon, K. E. (2000). Adaptability in the workplace: Development of a taxonomy of adaptive performance. Journal of Applied Psychology, 85(4), 612-624.

Quattrone, G. A., \& Jones, E. E. (1980). The perception of variability within ingroups and out-groups: Implications for the law of small numbers. Journal of Personality and Social Psychology, 38(1), 141-152.

Rasbash, J., Browne, W., Goldstein, H., Yang, M., Plewis, I., Healy, M., Woodhouse, G., Draper, D., Langford, I., \& Lewis, T. (2000). A user's guide to MlwiN. Multilevel Models Project Institute of Education, University of London.

Rust, R. T., Danaher, P. J., \& Varki, S. (2000). Using service quality data for competitive marketing decisions. International Journal of Service Industry Management, 11(5), 438-469.

Schneider, B., White, S. S., \& Paul, M. C. (1998). Linking service climate and customer perceptions to service quality: Test of a causal model. Journal of Applied Psychology, 83(2), 150-163.

Scott, S. G., \& Bruce, R. A. (1994). Determinants of innovative behavior: A path model of individual innovation in the workplace. Academy of Management Journal, 37(3), 580-607.

Sarin, S., \& McDermott, C. (2003). The effect of team leader characteristics on learning, knowledge application, and performance of crossfunctional new product development teams. Decision Sciences, 34, 707739 .

Seibert, S. E., Crant, M. J., \& Kraimer, M. L. (1999). Proactive personality and career success. Journal of Applied Psychology, 84(3), 416-427.

Sergeant, A., \& Frenkel, S. (2000). When do customer contact employees satisfy customers? Journal of Service Research, 3(1), 18-34.

Singh, J. (2000). Performance productivity and quality of frontline employees in service organizations. Journal of Marketing, 64(2), 15-34.

Smith, A. K., \& Bolton, R. (1998). An experimental investigation of customer reactions to service failure and recovery encounters: Paradox or peril? Journal of Service Research, 1(1), 65-81.

Snijders, T. A. B., \& Bosker, R. J. (1999). Multilevel analysis: An introduction to basic and advanced multilevel modeling. London: Sage.

Solomon, M. R., Surprenant, C., Czepiel, J. A., \& Gutman, E. G. (1985). A role theory perspective on dyadic interactions: The service encounter. Journal of Marketing, 49(1), 99-111.

Soteriou, A., \& Zenios, S. A. (1999). Operations, quality, and profitability in the provision of banking services. Management Science, 45, 12211238 
Spiro, R. L., \& Weitz, B. A. (1990). Adaptive selling: Conceptualization, measurement, and nomological validity. Journal of Marketing Research, 27(1), 61-69.

Spreitzer, G. M. (1995). Psychological empowerment in the workplace: Dimensions, measurement, and validation. Academy of Management Journal, 38, $1442-1465$.

Spreitzer, G. M., Cohen, S. G., \& Ledford, G. E., Jr. (1999). Developing selfmanaging work teams in service organizations. Group \& Organization Management, 24(3), 340-366.

Spreng, R. A., Harrell, G. D., \& Mackoy, R. D. (1995). Service recovery: Impact on satisfaction and intentions. Journal of Services Marketing, 9(1), 15-23.

Steenkamp, J.-B. E. M., \& Van Trijp, H. C. M. (1991). The use of LISREL in validating marketing constructs. International Journal of Research in Marketing, 8, 283-299.

Stewart, G. L. (2000). Meta-analysis of work teams research published between 1977 and 1998. Academy of Management Proceedings, Toronto.

Tajfel, H., \& Turner, J. C. (1985). Social identity theory of intergroup behavior. In S. Worchel \& W. G. Austin (Eds.), Psychology of intergroup relations. Vol. 2, Chicago: Nelson-Hall, 7-24.

Teigland, R., \& McLure Wasko, M. (2003). Integrating knowledge through information trading: Examining the relationship between boundary spanning communication and individual performance. Decision Sciences, 34, 262-286.

Van Looy, B., Desmet, S., Krols, K., \& Van Dierdonck, R. (1998). Psychological empowerment in a service environment: Some empirical findings. In T. A. Swartz, D. E. Bowen, \& S. W. Brown (Eds.), Advances in service marketing and management. Vol. 7, Greenwich, CT: JAI Press, 293-311.

Van Yperen, N. W., \& Snijders, T. A. B. (2000). A multi-level analysis of the demands-control model: Is stress at work determined by factors at the group level or the individual level? Journal of Occupational Health Psychology, 5(1), 182-190.

Vancouver, J. B., Millsap, R. E., \& Peters, P. A. (1994). Multilevel analysis of organizational goal congruence. Journal of Applied Psychology, 79, 666679.

Wageman, R. (1997). Case study: Critical success factors for creating superb selfmanaging teams at Xerox. Compensation and Benefits Review, 29(5), 31-41.

Wellins, R. S., Byham, W. C., \& Wilson, J. M. (1991). Empowered teams: Creating self-directed work groups that improve quality, productivity, and participation. San Francisco: Jossey-Bass.

Wels-Lips, I., Van der Ven, M., \& Pieters, R. (1998). Critical services dimensions: An empirical investigation across six industries. International Journal of Service Industry Management, 9(3), 286-309. 
Zeithaml, V. A., Berry, L., \& Parasuraman, A. (1996). The behavioral consequences of service quality. Journal of Marketing, 60(2), 31-46.

Ad de Jong is an assistant professor in the Department of Marketing and Marketing Research, Faculty of Economics and Business Administration, Maastricht University, the Netherlands. His main research interests are: consumer behavior, management of service operations, self-managing teams, services marketing, the service profit chain, linkage research, multilevel theory and research, and multichannel research. The journals in which he has published include Journal of Marketing, International Journal of Research in Marketing, Journal of Retailing, Journal of Service Research, and International Journal of Service Industry Management.

Ko de Ruyter is a professor of international service research at Maastricht University, the Netherlands and director of the Maastricht Academic Center for Research in Services (MAXX). He has published six books and numerous scholarly articles in, among others, Journal of Marketing, Journal of Economic Psychology, International Journal of Research in Marketing, Journal of Retailing, International Journal of Service Industry Management, Journal of Business Research, Journal of Service Research, European Journal of Marketing, Information and Management and Accounting, Organisation and Society. He serves on the editorial boards of various international academic journals, including Journal of Service Research and International Journal of Service Industry Management. His research interests concern international service management, e-commerce, and customer satisfaction and dissatisfaction. 